\title{
La anticipación de lo último. La teología fundamental de Wolfhart Pannenberg
}

\section{Jesús Martínez Gordo, Servicio Diocesano de formación del laicado, Bilbao.}

No cabe duda de que la teologla de Wolfahrt Pannenberg ejerce gran influjo sobre todo en los centros universitarios centroeuropeos, porque su finalidad principal es, ante todo, la de mostrar la verdad de la fe cristiana. En concreto trata de hacerlo a través de una concepción de la verdad como anticipación de lo último. Para Pannenberg, Jesús de Nazaret es la anticipación en la historia de la verdad delinitiva.

Por otra parte, los teólogos latinoamericanos de la liberación, y otros europeos, critican esta perspectiva si se la toma unilateralmente y, además, la consideran peligrosa cuando lleva, como ocurre en el caso de Pannenberg, al olvido de quienes mueren antes de tiempo (Bartolomé de las Casas y Gustavo Gutiérrez) o de quienes son martirizados (Jon Sobrino).

Indudablemente, sería muy oportuno el contraste entre ambas perspectivas. En este artículo, sin embarego, nos vamos a concentrar en la exposición del pensamiento fundamental de Pannenberg, remitiendo para un próximo libro el análisis de sus carencias con relación a la temática central de la teología de la liberación I. Y comencemos ya nuestro análisis.

La teología de Wolfahrt Pannenberg está profundamente marcada por tres inquietudes que se desprenden de su diagnostico y que marcan profundamente su perspectiva teológica.

I. En breve aparecerá un trabajo más detallado sobre Wolfhart Pannenberg titulado Anticipación de lo último y olvido de los últimos. La teología fundamental de Wolfhart Pannenberg. En este libro tendré la oportunidad de exponer el diagnóstico socio-teológico, la teología de la revelación y de la fe de nuestro autor para finalizar co una valoración de los puntos más importantes del sistema pannenberguiano. 
En primer lugar, trata de erradicar todo atisbo de autoritarismo teológico. Pannenberg reivindica, con $\mathrm{K}$. Barth, la centralidad de la revelación cristiana, pero piensa que el positivismo de la revelación en que desemboca la teología de $\mathrm{K}$. Barth no es el conducto más adecuado para reivindicar la primacía del Dios predicado por Jesús de Nazaret.

En segundo lugar, rechaza todo subjetivismo irracional. El pietismo y la reducción existencial de la Escritura son una indicación de que la teología desmitologizadora ha caído en la irracionalidad. El pietismo bultmanniano no pasa de ser, al fundamentar la fe cristiana sobre la decisión de creer, sino otro rostro - uno más- del subjetivismo irracional.

En tercer lugar, Panneberg está seriamente preocupado por superar el ateísmo, sobre todo, el de corte antropológico. El ateísmo modemo ha sacudido violentamente los hasta ahora ślidos cimientos en los que se apoyaba la teologra, y a partir de tal sacudida ya no es posible pensar de la misma manera. Hoy son evidentes las sospechas, de tanto calado y trascendencia, que no se pueden eludir ni obviar apelando a la decisión, a la opción, a la gracia o, en definitiva, a la pura subjetividad humana. Se impone dar razón de la verdad cristiana, empleando los mismos o parecidos criterios que han desplegado los llamados maestros de la sospecha.

Según esto, el autoritarismo barthiano, el subjetivismo bultmanniano y la increencia en que desemboca el proceso de secularización serán las tres referencias permanentes en la teología de Pannenberg. Todas ellas se caracterizan, según el diagnóstico que realiza nuestro autor, por su incapacidad de dar cuenta tanto de la dimensión religiosa que constituye al sujeto humano, como de la verdad que se ha mostrado en Jesús de Nazaret y en las religiones históricas. Consecuentemente, una teologfa responsable ha de tener en cuenta las legítimas exigencias que brotan del diagnóstico socio-teológico, así como atender a la verdad de la revelación y de la fe cristiana. En este doble objetivo general quedan inscritos otros objetivos especfficos.

\section{Objetivos específicos de la teología}

La mirada de nuestro autor a la teología luterana más reciente le lleva a percatarse de la escasa atención prestada en ella al conocimiento racional. La luterana es, en efecto, una teología repleta de convicciones y fuertemente testimonial, pero difícilmente aceptable por quien cuestiona la entidad misma de Dios.

\subsection{Una teología de la fe que dé primacía al conocimiento racional}

Para Pannenberg es preciso elaborar una teología que preste más atención al conocimiento racional y que explicite la entidad de la fe cristiana desde dicho 
conocimiento. Tal tarea ha de realizarse (a) repensando las relaciones entre las convicciones de fe y la crítica racional, (b) adentrándose en la antropología (como saber en el que el ateĺsmo ha planteado con más crudeza la batalla por el sentido de la fe cristiana) y (c) incorporando a la reflexión teológica las conclusiones que se derivan de la historia de las religiones, así como la pretensión de Jesús de ser la anticipación de la verdad final.

Asf́, pues, la filosofía (sobre todo, la de corte onto-teológico), la antropología (con todas sus adquisiciones más recientes) y la historia (como historia de las religiones y lugar de revelación, confimmación y anticipación de Dios en Jesús), se convierten para Pannenberg en las referencias permanentes de su sistema.

\subsubsection{Articulación de la fe y la crítica racional}

La teología cristiana moderna, diagnostica Pannenberg, no ha sido capaz de afrontar, como en su día lo hizo la patrística y la escolástica, el reto de hacer significativa la verdad del evangelio en un nuevo paradigma de corte antropológico, y éste es un problema de fondo que subsiste desde entonces. En vez de afrontarlo, la teología se ha limitado a refugiarse en la Escritura y a distinguir el saber natural (resultado de la adecuación del concepto con la realidad) del conocimiento sobrenatural (recibido de Dios por medio de su palabra)2. El curso de los años se ha encargado de ir independizando lo natural hasta llegar a contraponerlo a lo supuestamente sobrenatural y revelado. La teología ha acabado por convertirse de esta manera, en una ciencia positiva de la revelación, en algo superfluo e irrelevante a los ojos del pensar natural.

Si es cierta la incapacidad de la teología moderna, también lo es el progresivo empequeñecimiento de la razón. Esta ha ido perdiendo su imparcial apertura y solicitud para acoger el ministerio, olvidando que en todo conocer opera la confianza. Una teologia responsable, sostiene Pannenberg, no ha de incurrir en el error de rechazar la razón, sino que ha de hacer un uso diferenciado de ella, contribuyendo, de esta manera, a superar las reducciones autoritarias en que ha caído3.

En conclusión, la teología y la filosofía —en particular, la epistemologíahan ido favoreciendo la separación entre la verdad en que se enraízan las con-

2. Cfr. W. Pannenberg. "Die Krise des Schriftprinzips", en Grundfragen systematischer Theologie. Gesammelie Aufsälze, Görtingen, 1971, pp. 20-21.

3. Cfr. "Glaube und Wirklichkeif in G. Von Rad", en H. W. Wolf, R. Rendtorff, W. Pannenberg, Gerhard von Rad. Seine Bedeurung für die Theologie, München, 1973. Pannenberg enjuicia su propia teologla, en M. Fraijo, El sentido de la historia Introducción al pensamienso de W. Pannenberg, Madrid, 1986, pp. 269 y ss (en adelante este escrito será citado como $M$. Fraijó). 
vicciones y la crítica racional. Una de las tareas que Pannenberg asigna precisamente a su teología de la fe consiste en mostrar la consistencia racional de dichas convicciones para evitar en ellas cualquier atisbo de irracionalidad y autoritarismo. "Sólo la reflexión racional puede conducir al convencimiento de que la revelación crisliana es algo bien fundado y consistentet.

\subsubsection{Articulación entre saber y experimentar}

Cada día parecen ser más los que consideran que la religión es, como consecuencia del proceso secularizador, una necesidad secundaria, una componente no constitutiva del ser humano. Tal conclusión vendría avalada no sólo por la reflexión lïlosófica sobre Dios o por la retirada de la teología a los cuarteles de invierno del subjetivismo y del positivismo de la revelación, sino también por la creciente dificultad que presentan las mismas afirmaciones religiosas para expresar con un mínimo de rigor una verdad universalizable y no reconducible a mero comportamiento psicológico y, o sociológico.

Un sector del pensamiento contemporáneo cuestiona, en efecto, que la dimensión religiosa sea constitutiva y constituyente de la propia naturaleza humana, a la vez que independiente de la fantasía humana. Es, una vez más, la crítica atea de la religión en el campo de la antropología.

Afrontar esta crítica implica justificar racionalmente la religión y la fe cristiana sobre el terreno de la misma antropologfa. En consecuencia, una teologla de la fe que pretenda ser significativa ha de apropiarse críticamente de la investigación antropológica no teológica y ha de mostrar a partir de ella la universalidad de la experiencia religiosa y su razonabilidad5. Ha de ser una antropologia teológica ocupada en mostrar la entidad y alcance de lo que se puede llamar, a partir de la experiencia del nexo simbiólico entre la madre y el niño, la radicación y la destinación atemática. Dicho nexo es el fundamento de una experiencia de confianza que posibilita y sostiene la apertura del ser humano al mundo y que se enraíza, aunque sea inconsciente y atemáticamente, en Dios, como Juturo del ser humano6.

4. W. Pannenberg en M. Fraijó, pp. 267. Cfr. ibid., pp. 266-267: "Es preciso combatir el prejuicio de que la pretensión de verdad de la predicación cristiana carece de validez universal y de consistencia objetiva. En el camino hacia el cristianismo tiene que existir un interés por él y por su estudio. Este interés puede surgir de manera más o menos causal. Por tanto, la reflexión racional sola no puede ser un camino de acceso al cristianismo (...). En cambio, la consistencia de la revelación cristiana solo puede ser juzgada analizando su contenido. Para ello es necesaria la investigación racional".

5. Cfr. Anthropologie in theologischer Perspektive, Göttingen, 1983, pp. Il-23.

6. Cfr. ibid., pp. 219-220. 
El análisis de dichas radicación y destinación atemáticas no demostrará la existencia de Dios. Se limitará, y no es poco, a mostrar que la relación del ser humano con la temática de naturaleza religiosa es algo constitutivo. Ślo de esta manera, puede ser invalidado el ateísmo de corte antropológico en su propio terreno?.

Pannenberg reivindica y fundamenta así la prioridad de la experiencia sobre el saber, pero no para caer en las garras, una vez más, del irracionalismo o del subjetivismo. La experiencia singular nunca confiere una evidencia, sino una certeza que necesita ser clarificada y confirmada en el curso de la historia. En toda certeza subjetiva se experimenta, por tanto, una anticipación de la verdad última, a la espera de su confirmación definitiva al final de la historia.

Pero la categoría de experiencia liene en la teología de Pannenberg una inusitada relevancia no sólo melodológica, sino también sistemática. Para hablar de Dios, sostiene nuestro autor, es preciso experimentar en toda su radicalidad el fundamento del mundo, del ser humano y de la historia. Dios, la realidad que todo lo determina8, se manifiesta en estas realidades. $Y$ a la inversa, el mundo, el ser humano y la historia encuentran su razón de ser y su plena realización en la glorificación de su creador'.

Esto quiere decir que la teologla fundamental ha de arrancar de la experiencia de Dios en la realidad y, a la vez, ha de posibilitar experimentar o aproximarse a experimentar dicha presencia. La experiencia de Dios, provisional y permanentemente pendiente de una comprobación definitiva, está llamada a convertirse en un criterio de indudable calado en la teología.

\subsubsection{Articulación entre provisionalidad y definitividad}

La reflexión metafisica es central en el sistema teológico de Pannenberg, pero, por sI sola, puede degenerar en mero constructo abstracto e insignificante. Igualmente, la antropologia, sin relación con la verdad filosofica y la historia, corre el peligro de degradarse, hasta llegar a ser una mera y simple expresión de sentimientos y deseos.

7. Cfr. ibid., p. 227; Systemarische Theologie, pp. 57-58; M. Fraijo, p. 274: Pannenberg sostiene, al hilo de su reflexión sobre la diferencia entre la filosoffa de la religión y la teología fundamental, que la modema antropología se ha convertido en el campo de discusión critica de los proyectos antropológicos seculares con la finalidad de descubrir las implicaciones religiosas de la realidad humana.

8. Cfr. Wissenschafistheorie und Theologie. Frankfurt, 1973, p. 304.

9. Cfr. Systematische Theologie, pp. 71-72. Cfr. ibid, p. 192s, donde recuerda que la verdad de la religión se va mostrando en el proceso de la experiencia del mundo y en el continuado intento de comprobar la idoneidad de la interpretación propuesta. Todo se encuentra, por ello, sub ratione Dei. 
La historia es, por ello, el tercer pivote sobre el que descansa la reflexión de Pannenberg y, por extensión, su teología de la fe. En efecto, la reflexión ontológica se convierte, sin la mediación de la historia, en mera abstracción; de la misma manera que la investigación antropológica puede degenerar, sin la referencia a la historia, en constatación de una apertura sin objetivo. La reflexión y la antropología necesitan contrastarse con la historia, porque sólo asI se evitará incurrir en el subjetivismo que constantemente bordean ambos modos de proceder.

Por consiguiente, la historia es importante no sólo para salir al paso de todo posible exceso subjetivista, sino también, y sobre todo, para captar la presencia y la objetividad de Dios que postulan la antropología y la filosofía. Su función no es sólo terapéutica y preventiva, sino también propositiva.

El análisis de los archivos históricos que son las religiones permite captar, apunta Pannenberg, a cómo la revelación de Dios en la historia es provisional y cómo la historicidad forma parte de la identidad misma del Dios que se revela. Sostener esta posición no equivale a incurrir en un craso relativismo teológico, ya que tanto la verdad como Dios se muestran estables en el decurso temporal. Sucede, más bien, que relativiza la idea de absoluto. Esta, efectivamente, desaparecerá con la aparición defínitiva de la divinidad. Entre tanto, la absolutez de la verdad sólo se nos hace accesible en la relatividad de la experiencia y de la reflexión. Esto significa que el sujeto humano jamás está en condiciones, mientras la historia continúe, de determinar definitivamente el verdadero significado de las cosas y de los acontecimientos. Sólo son posibles anticipaciones provisionales del final 10 .

Por tanto, la teología ha de partir, para que efectivamente sea discurso sobre Dios y no mero producto de la fantasía humana, de la autorrevelaciación de Dios en la historiall y del estudio de sus archivos históricos, que son las religiones.

\subsection{Una teología de la fe en diálogo con la ilustración y la increencia}

La teología de la fe que se propone realizar Pannenberg está presidida no sólo por la centralidad que en ella se concede a la razón epistemológica, antropológica e histórica, sino también por el interés en dialogar con la ilustración y la creencia.

El diálogo, al menos como lo entiende y practica Pannenberg, ha de aceptar -cuando menos metodológicamente- el primado del conocimiento racional,

10. Cfr. ibid., p. 65.

11. Cfr. ibid., p. 196. 
asi como la centralidad de la libertad y del pluralismo que rejvindica la ilustración 12 .

Pero el diálogo no ha de limitarse a asumir las indudables conquistas. También implica criticar la ambivalencia de la modernidad, sin dejar de reconocer, por ello, las limilaciones de la teología luterana. El diálogo crítico pasa por reivindicar la libertad frente a todo tipo de autoridad; no sólo, por tanto, frente a los contenidos autoritarios de la tradición, sino también frente a los propios prejuicios -igualmente autoritarios- de cada épocal3.

Pero la crítica, ya sea de los prejuicios propios como de los ajenos, ha de ceder el paso a la verdad de la fe cristiana. Una crítica que, en algún momento de su proceso no fuera propositiva, se negaría a mostrar la consistencia de la verdad que defiende.

\section{Una teología de la fe netamente abierta y ecuménica}

La teología de la fe que propone y desarrolla Pannenberg pretende ser ecuménica. Intenta ser, al tomarse con seriedad su carácter provisional, una teología que vaya erradicando todo atisbo de dogmatismo e intolerancia entre las diferentes confesiones.

La problemátical4, característica propia de toda afirmación firme, ha de permitir una teología abierta a la verdad; una verdad de la que también se hacen cargo, no se ha de olvidar, otras religiones y otras confesiones cristianas.

12. La teologla de Panennberg también estâ presidida por una convicción de la que intenta dar razón constantemente: los criterios de la modemidad ilustrada, y aún los de la misma increencia, son una versión secularizada de los ustentados por la tradjción bßblica. Por tanto, una teologia de la fe responsable no se ha de limitar a exponer las implicaciones religiosas de la realidad - algo reservado a la antropologia teológica fundamental- sino que ha de llegar a mostrar las implicaciones cristianas de dicha realidad. $C f r$. M. Fraijo, pp. 34-35, en que rcoge, no sin una cierta irónica crispación, esta pretensión de Pannenberg. Este, sostiene Fraijo, "no trata de hacer una teologla pensando únicamente en los fervorosos, en los dispuestos a arrojarse generosamente al vacío. Es necesario pensar en los paganos, en los que sólo dicen sí cuando las razones y los argumentos los convencen. A ellos se dirige el apologeta Pannenberg (...). La maniobra de Pannenberg era perfecta: somete su teología a los criterios de la modernidad pero, a la vez, declara sin paliativos que estos criterios son herencia - una herencia secularizada - de la tradición bíblica. EJ valor universal del cristianismo queda asi brillantemente puesto de relieve. Lo cristiano es la matriz, la base del mundo modemo. Cristianismo y modemidad no son dimensiones antogónicas".

13. Cfr. Wolfhart Pannenberg, en M. Fraijó, p. 286.

14. Cfr. Wolfhart Pannenberg, en M. Fraijo, p. 272. 
La erradicación de todo dogmatismo e intolerancia no supone sancionar, ni mucho menos, una especie de relativismo teológico que en la práctica es una renuncia a la verdad y a su universalidad. Si es cierto -en la propuesta leológica de Pannenberg - que sólo al final concluirán los debates (porque sólo entonces se alcanzará la verdad definitiva) no es menos cierto que en el presente se va anticipando dicha verdad. Que la verdad sea lo que será no quiere decir que no exista ya en el momento actual, sino que espera su verificación última en el futuro.

En definitiva, la teologia de la fe que pretende elaborar Pannenberg es ecuménica no sólo porque se esfuerza en desterrar toda señal de dogmatismo e intoleracia, sino también porque se afana en ofrecer formulaciones teológicas con pretensiones de validez universal y, por tanto, a la espera de su confirmación. Sólo así es posible ir superando las contraposiciones doctrinales que dividen a las diferentes religiones 15 y evitar el relativismo, tan disolvente como el dogmatismo que nos ha precedido.

\subsection{Una teología desde abajo y desde la unidad de Dios con el ser humano}

Las urgencias que brotan del diagnóstico socio-teológico llevan a que Pannenberg subraye con inusitada fuerza, al menos en sus primeros años, la necesidad de elaborar una cristología y, por lo tanto, una teología desde abajo. "Los plantamientos cristianos-primitivos del pensar cristologico han surgido de abajo, es decir, a partir de la pretensión de poder de Jesús confirmada por el acontecimiento pascual" 16 .

Es característico de la teología desde arriba presuponer, indica Pannenberg, la divinidad de Jesús y resaltar su encarnación. Sus partidarios (desde Ignacio de Antioqufa, los apologistas del siglo $\Pi$ hasta, más recientemente, K. Barth, $\mathrm{E}$. Brunner y $\mathrm{H}$. Vogel entre otros) parten del dogma de la trinidad para preguntarse por la manera cómo la segunda persona ha asumido una naluraleza humanal7.

15. Cfr. Wolthart Pannenberg, en $\mathbf{R}$. Gibellini, Teologia e ragione. lienerario e opera de Wolfhart Pannenberg, Brescia, 1980, pp. 294-295.

16. Fundamentos de cristología, p. 164; ibid, pp. 27-63. Veáse en la p. 60 cómo justifica su apuesta por la teología desde abajo para evitar que se interprete como proyección en sentido feuerbachiano, riesgo que ronda a toda teología y cristologla presidida por un interés soteriológico.

17. Cfr. ibid., pp. 43-45; "Was ist eine dogmatishe Aussage?", en Grundfragen Systematischer Theologie. Gesammelse Aufsatze, Goutingen, 19712. p. 175: "De las formulaciones doxológicas no se pueden extraer conclusiones lógicas porque ello equivaldría a transponer el contenido finito de un concepto de Dios. No es posible desarrollar deductivamente conclusiones teológicas conexas a partir del concepto de Dios. La conexión de las afirmaciones teológicas entre sí nunca es concebible sino a 
Este tipo de teología deductiva presupone, al depender de una preconcepción filosoffica de la divinidad, la existencia de Dios. Es así como diluye el espesor histórico de Jesús y del Dios que actúa en él18. Acaba siendo una teologla que ignora los condicionamientos históricos en los que se mueve toda representación de Dios.

Es propio, en cambio, de una teología inductiva partir de la humanidad historica de Jesús y remontarse, basándose en el mensaje y en el destino histórico del Nazareno, al reconocimiento de su divinidad. En este modo de proceder se llega al misterio de la encarnación sólo al final de esta ascensión históricometodologica. Se impide disolver la teologia, a diferencia de lo que sucede con la vla deductiva, en una especie de filosofía cristiana, puesto que se renuncia partir de una idea de Dios que no esté cimentada sobre la historia misma de hijo de María. Jesús y su destino desbaratan, por tanto, cualquier conocimiento previo de la divinidad, incluso el conocimiento previo con el que todo sujeto humano se acerca a Dios 19. Así, pues, los hechos históricos fundamentan, según nuestro autor, la fe al no sobrevenir a los acontecimientos el carácter revelador como algo adicional, sino como algo intrínseco a ellos 20 .

La cristología y la teología inductivas permiten mostrar, por tanto, en qué medida una afirmación es conforme con la figura histórica de Jesús, pero apuntará autocríticamente Pannenberg más tarde- - no logran pensar la revelación de Dios en Jesús de Nazaret en su contenido propio. En efecto, este modo de proceder teológico no logra mostrar "la unidad de Dios con el hombre Jesús de Nazaret'21.

El decantarse de la reflexión le llevará a reconocer, por consiguiente, que una teología hecha única y exclusivamente desde abajo corre el riesgo de no

la inversa, es decir, mediante una profundización en el acontecimiento en que Dios se ha revelado".

18. Cfr. Pannenberg. "Christologie et thélogie". Les quatre fleuves 4 (1975) 89-90. El tono de las observaciones crílicas que efectúa nuestro autor es el siguiente: el Dios que se manifiesta en este tipo de teología es un Dios pensado como existente previamente a su encarnación. Si es asl ¿cómo pensar la unidad de Jesús con Dios si su ser divino existe independientemente del acontecimiento de la revelación? ¿No se está sosteniendo en la práctica la irrelevancia de este acontecimiento? ¿Cómo puede revelar a Dios un acontecimiento tan extrínseco a su ser? Este tipo de cristologías y de teologías no han conducido, al menos hasta el presente, al Jesús histórico de Nazaret. Fracasan porque no alcanzan a pensar la figura histórica de Jesús a partir de Dios.

19. Cfr. Fundamentos de cristología, p. 47.

20. Cfr. ibid, pp. 36-39.

21. Christrologie es théologie, p. 88. 
tematizar el objeto propio de loda cristologla y de toda teología: la verdad de la unidad de Dios con Jesús de Nazarel y, por extensión, de Dios con todos los seres humanos22.

Ambas teologías, la más clásica que parte del misterio de la encarnación y la más moderna que arranca desde abajo, tienen un mismo defecto: presuponen una idea de Dios diferente y ajena a la historia de Jesús. Esto quiere decir que ni una perspectiva ni otra pueden pensar, por sí solas, a Dios como revelado en Jesús ni la unidad de Dios con él.

El punto de partida de la cristología y de la teología no puede ser solamente el hombre Jesús separado de su relación con Dios, sino inserto en el contexto de las tradiciones religiosas de su pueblo y en la historia religiosa de la humanidad. Esas son las vías seguidas por Dios para revelarse. Una comprensión específicamente cristiana no excluye, pues, la palabra sobre Dios fuera del cristianismo23.

Por consiguiente, una teología es desde abajo en la medida en que recupera con firmeza la figura histórica y la relación de Jesús con Dios, asi como la confirmación por parte de Dios de la pretensión de Jesús24.

\subsection{Elaboración de una teología doxológica}

Toda teología que pretenda dar razón de la verdad de Dios y que sea sensible a la mentalidad contemporánea ha de afrontar el problema del método que emplea. Ha de ser, en efecto, una teología cercana al sujeto moderno (para poder ser significativa), pero no fundamentada en él (si es que no quiere inducir a pensar que Dios y la teología son productos de la lantasla humana). Y ha de ser, a la vez, un discurso que exprese la verdad de Dios (sin caer en la teologla racional), reconociendo que Dios sólo puede ser conocido mediante Dios mismo, mediante su revelación en la actuación histórica de Jesús 25 .

Si ya no es de recibo una teología irracional y subjetivista -amante de subrayar la radical alteridad de la divinidad y, por tanto, cargada de expresiones dialécticas y equívocas- tampoco lo es una teología que pueda degenerar en racionalismo y que niegue la problematicidad de Dios y su revelación.

¿Es posible hablar fundadamente de Dios sin violentar, mediante artilugios racionalistas, su misterio y sin incurrir en subjetivismos que hagan insignificante todo discurso teológico? Renace el viejo problema de la idoneidad o no del

22. Cfr. ibid., p. 90.

23. Cfr. ibid., pp. 90.82 .95 .

24. Cfr. ibid., p. 86: "el hombre Jesús de Nazaret no es accesible sin su Dios".

25. Cfr. Systematische Thoeologie, pp. 11-16. 
lenguaje analógico, descartados los de corte equívoco y unívoco para hablar de Dios.

Cuando la teología actual aborda el problema de cómo hablar fundadamente de Dios se encuentra con, al menos, tres propuestas de solución que o bien subrayan la razón analógica o la analogia entis (E. Przywara y con él H. U. von Balthasar y la gran mayoría de los católicos); o bien acentúan la analogla de la fe o analogia fidei (K. Barth, y con el la gran mayoría de los luteranos), o bien propugnan, tal es el caso de Pannenberg, la concepción doxológica de la teología.

Mediante la analogía26 se ha intentado desarrollar un discurso sobre Dios que, explicitando su diferencia con las criaturas y con el mundo, salvaguarda su divinidad. En tal discurso se afima a la vez que la semejanza gnoseológica del mundo con Dios una desemejanza todavía mayor de orden ontológico entre ellos (in tanta similitudo, maior dissimilitudo)27.

Esta distinción, apunta críticamente nuestro autor, entre semejanza gnoseologica y desemejanza onlologica no se ha respetado debidamente ya que han sido muchos los teólogos, sobre todo escolásticos, que han acabado creyendo que su discurso era una explicitación de la naturaleza misma de Dios. Esta enorme equivocación se ha ido consolidando en la medida en que ha ido entendiéndose que la analogía era el mecanismo lógico que permitía determinar lo desconocido (Dios) a través de lo conocido (lo creado). Se suponía que en Dios se encontraba el mismo e idéntico logos que en lo creado. Se acababa por establecer, de esta manera, una correspondencia -ilegftima, por cierto- entre el discurso sobre Dios a partir de la creación y su misma naturaleza.

El intento más reciente de E. Przywara28 por comprender la analogía, en continuidad con el Concilio Laterense IV (1215), como una reductio in mysterium (Deus semper maior) tampoco ha aportado, sostiene Pannenberg, gran luz ya que no ha sido capaz de solucionar el problema de cómo es posible articular la entidad del misterio con la búsqueda del logos. Su acentuación de la desemejanza atenta, según Pannenberg, contra el núcleo de la analogía, que no es otro que buscar un logos común. Y, a la vez, esta tendencia a investigar lo desconocido a partir de lo conocido (algo permanentemente presente en el pensamiento analogizante) entra en conflicto con la intención de la reductio in mysterium. La solución propuesta por E. Przywara, aunque bienintencionada, no acaba, pues, de solucionar el problema de fondo que late en la doctrina de la

26. Cfr. "Was ist eine dogmatische Aussage?", en Grundfragen systematischer Theologie. Gesammelte Aufsaize, p. 174 y ss; "Analogie und Doxologie" en ibid., p. 181-201.

27. Cfr. ibid., p. 189.

28. Cfr. ibid., p. 189s. 
analogía: cómo hablar correclamente de Dios sin violentar su misterio insondable29.

De entre los teólogos luteranos ha sido $\mathbf{K}$. Barth quien se ha opuesto con más radicalidad, sobre todo en su primer época, a la doctrina de la analogia entis, proponiendo la analogia fidei o revelationis. Barth no aceptará la doctrina de la analogia entis porque viene a asemejar a Dios y a la criatura, abarcándolos en un concepto superior y omnicomprensivo. Este concepto superior es el que permite construir una teología natural que se caracteriza, entre otros puntos, por no respetar a Dios en su misterio insondable y por acabar reduciendo la teología a mera y simple antropología. Por esta razón, Barth llegará a sostener, en contraposición a Przywara (para quien la analogia entis es la manera católica de hablar de Dios) un posicionamiento claro, neto y rotundo: "considero a la 'analogia entis' como la invención del Anticristo y creo que justamente por causa de clla no se puede llegar a ser católico" 30 .

Una reconsideración de esta radical postura lo llevará más tarde a admitirla como regla hermenéutica y como regla de correspondencia con la revelación histórica. La analogía como regla hermenéutica permite que un texto bíblico oscuro sea interpretado por relación con otros textos más claros, así como en relación al contenido global de la fe cristiana. La analogía como regla de correspondencia permite mostrar, por su parte, la viabilidad del discurso humano sobre Dios, en la medida en que tal discurso está en correspondencia con la realidad divina que se autorrevela. Sólo es posible hablar fundadamente sobre Dios a partir de Dios mismo.

Este es el núcleo de la analogia fidei barthiana. Y éste es, precisamente, el punto que le separa con más radicalidad de Pannenberg ya que en la reinterprelación que Barth efectúa de la analogía se encuentra la raiz del positivismo autoritario, aś como de su comprensión reductiva de la revelación como palabra.

H. U. von Balthasar ha pretendido establecer, más recientemente, un puente entre las posiciones de Barth y Przywara defendiendo, a partir de los padres y de la escolástica, la importancia de la analogia entis como procedimiento que permite reconocer, con Barth, la centralidad indiscutible de la analogia fidei o de la analogia revelationis ${ }^{31}$.

Pannenberg no comparte este intento mediador de von Balthasar, porque considera que en su revisión de la doctrina de la analogía se sigue dando la

29. Cfr. Wolfhart Pannenberg, Analogie und Doxologie, en Grundfragen systematischer Theologie. Gesammelre Aufsätze, 19712, pp. 191-192, 216-217.

30. Die Kirchliche Dogmarik, Band I, Teil VIII-IX (1982). Considera que el resto de las molivaciones para no ser católico están desprovistas de entidad.

31. Cfr. Karl Barth. Darstellung und Deutung seiner Theologie, Köln, 1951. 
primacía a todo aquello que es correspondencia y, o semejanza entre Dios y la creatura. Persiste el riesgo, por tanto, de confundir el discurso humano sobre Dios con la naturaleza de Dios mismo. Rechaza, en definitiva, esta concepción de la analogía, porque cree que con ella se violenta la trascendencia y el misterio.32 y, justamente por ello, propone la alternativa de la doxologfa.

Lo propio de un auténtico teólogo no es tanto, sostiene Pannenberg, el raciocinio, sino, más bien, la adoración de Dios. Todo discurso teológico es doxológico al no estar referido a una acción singular de Dios, sino a Dios mismo en lo que es desde siempre por su actuación en el mundo, en la historia y en el sujeto humano.

\subsubsection{La experiencia de la totalidad en la singularidad}

Es posible hablar fundamentalmente de Dios, tal es la posición de Pannenberg, a partir de la manifestación de la totalidad en la singularidad33. Lo singular e individual está inmerso, en efecto, en la totalidad. Por consiguiente, la idea de totalidad resulta de pensar la realidad y nuestra misma existencia como asentadas sobre una unidad que transciende lo que encontramos en torno a nosotros mismos y que, precisamente por su capacidad de transcender e iluminar la totalidad de la realidad, convenimos en llamar Dios ${ }^{34}$.

Es evidente, por tanto, que nuestros diversos modos de comprender la totalidad de lo real (Dios) están influenciados y fundamentados en las experiencias concretas de la singularidad. Pero también es verdad que las experiencias singulares reciben una luz nueva gracias a su inserción en el todo; gracias, por ello, a nuestra experiencia de Dios.

Pannenberg no tiene ninguna dificultad en reconocer que cuando el sujeto habla de Dios lo hace en analogia con su experiencia del mundo3s. Sin embargo, no es lo mismo el discurso sobre Dios (basado en las transposiciones analógicas) que la naturaleza misma de Dios. El hablar sobre Dios no da pie para suponer que nuestras palabras impliquen, necesariamente, desvelamiento

32. Cfr. lo que escribe en J. M. Robinson-B. Cobb (eds). Theologie als Geschichse, Zürich-Stuttgart, 1967, p. 236.

33. No se ha de olvidar que se habla del actuar divino por referencia a acontecimientos concretos. los cuales, sin embargo, pueden ser también descritos, de manera diversa, prescindiendo de toda referencia de Dios.

34. Cfr. Analogie und Doxologie, pp. 194-195.

35. Cfr. ibid, pp. 198-199, donde declara como antropomorfismo el concebir a Dios, por ejemplo, como persona. Tales transposiciones no son, sin embargo, fruto de la fantasía, ya que lo normal es que estén fundadas sobre la peculiaridad del acontecimiento singular, en cuanto experimentado y anunciado como un actuar de Dios. 
alguno de su esencia divina36. La tcología es, por ello y antes que nada, adoración del misterio divino y sólo posteriormente discurso - siempre provisional e hipotético- sobre el misterio anticipado en el destino histórico y en la predicación de Jesús.

Así, pues, el discurso doxológico prescinde del criterio de correspondencia (propio de los griegos) entre el discurso sobre Dios y Dios mismo, se asienta en la percepción de la totalidad en lo singular, así como sobre el carácler proléptico o anticipatorio de la revelación de Dios en el destino histórico de Jesús ${ }^{37 .}$

Todo teólogo con perspectiva doxológica es consciente de que va más allá de los límites de la propia finitud y de que, por lo tanto, se eleva a la idea del Dios infinito ${ }^{38}$. De ahl que las afirmaciones doxológicas no puedan ser consideradas, por la transposición analógica en que se asienta su formalización, como afirmaciones incuestionadas e incuestionables ${ }^{39}$.

En los asertos sobre Dios desaparece la evidencia conceptual de los conceplos en ellos empleados. Desde el momento en que se aplican a Dios, se convierten en un acto de adoración de la infinitud de Dios40.

Toda afirmación doxológica está fundada, por consiguiente, sobre la experiencia de la plenitud que provoca la radicación en el poder de la totalidad; plenitud que sólo al final se acogerá en su evidencia irrefutable e incuestionable. Los enunciados doxológicos son, por esta razón, provisionales, porque provisional y mediada es nuestra experiencia de Dios y porque es propio de toda experiencia religiosa permanecer abierta a la infinita libertad divina. La provisionalidad y la relatividad caracterizan el discurso doxológico4l.

\subsubsection{La anticipación del futuro en el presente}

Ahora bien, afirmar la relatividad y provisionalidad de todo discurso sobre Dios no quiere decir que no sea posible una verdad sobre él. La relatividad está referida, en cuanto tal, a la idea de absoluto, pero no a la naturaleza y verdad del absoluto mismo. Nosotros podemos acceder $\longrightarrow$ y de hecho accedemos - a la

36. Cfr. ibid., p. 192.

37. Cfr. Fundamentos de cristología, p. 229: "el elemento doxológico de los asertos cristológicos está fundado en su carácter proléptico".

38. Cfr. Systematische Theologie, p. 66.

39. Cfr. Analogie und Doxologie, p. 186.

40. Cfr. Fundamentos de cristología, p. 229.

41. Cfr. Analogie und Doxoligie, pp. 87-188; Fundamentos de cristología, p. 229, nota 165: "se trata de una proyección hacia el futuro de Dios que únicamente se llevará a cabo con el pleno conocimiento de su esencia". 
absolutez en la relatividad de la experiencia singular, aunque no estamos en condiciones de determinar definitivamente, mientras exista devenir histórico, el verdadero significado de las cosas y de los acontecimientos de nuestro mundo.

Pero esto no quiere decir que el discurso sobre Dios no sea verdadero, sino que va cambiando, a la vez que se profundiza. En el decurso de tal proceso se va a afianzando -en contra de lo que sostienen los relativistas- el núcleo histórico de la idea de Dios y de su autorrevelación en la historia; aunque no se conserven necesariamente las formulaciones tal cual, al estar sometidas al vaivén de los cambiantes horizontes de comprensión ${ }^{42}$.

La anticipación del final es la llave maestra que abre la puerta de la verdad. El proceso histórico posibilita que el sujeto humano vaya accediendo a la verdad de Dios en medio de toda su provisionalidad, porque es en su seno donde se anticipa dicha verdad. De esta forma, Pannenberg pretende elaborar, en delinitiva, una teología capaz, a la vez, de respetar debidamente el misterio de Dios y de hablar fundadamente sobre él a partir de su anticipación en la historia.

Doxologia, experiencia de la totalidad de la realidad y prolepsis o anticipación se convierten en los ejes que, de hecho, ocupan una indiscutida centralidad en la teología de Pannenberg.

\section{Objetivos específicos de la teología de la revelación}

La teología de Pannenberg es una permanente pugna por erradicar toda señal de subjetivismo irracional y todo rastro de autoritarismo. Si es cierto que el irracionalismo subraya la certeza personal de la fe ( $y$, por tanto, la centralidad de la experiencia de Dios), no es menos cierto que este lipo de teología se desentiende de la entidad misma de la verdad. El autoritarismo, por su parte, tiene razón, cuando reivindica la centralidad de la objetividad y la primacía de la verdad. Su peligro mayor estriba en que no respeta la libertad del sujeto histórico y en que no es, por ello, suficientemente seductor. Esta clase de teología encubre, en su autoritarismo formal, un subjetivismo de fondo; algo que se puede apreciar en K. Barth.

Pannenberg pretende desarrollar, como contrapartida a estas dos extralimitaciones, una teología que se asiente sobre el peso de los argumenlos. Es preciso atreverse a elaborar. después de decenios de teologías marcadamente subjelivistas, una reflexión que sea capaz de certificar la universalidad y la verdad de la revelación, sin recurrir para ello a la decisión o a la opción y sin apelar a instancias autoritarias - sean axiomas o dogmas que supongan un atentado a la libertad investigadora.

42. Cfr. Systematische Theologie, pp. 65-66. 
Nuestro autor pretende mostrar, dejados al margen subjetivismos irracionales y autoritarismos temerosos, la verdad de la revelación cristiana a partir de su mismo contenido y sin renunciar a una confirmación de tal verdad en la experiencia y en la reflexión que el sujeto humano efectúa tanto del mundo como de sí mismo 43 . Ha de ser posible, si la realidad y el ser humano están referidos a Dios como a su fundamento y futuro, no sólo un discurso racional o razonable sobre él, sino también una confirmación sostenida en la historia de esta radicación y destinación a la divinidad. Sólo aś será posible elaborar una teología creíble y capaz de mostrar a Dios como el fundamento del mundo y de la existencia humana 44 .

Por su parte, la conciencia religiosa emerge cuando se tematiza la radicación y destinación atemática de toda experiencia cotidiana de sentido. La pregunta por la revelación y por su verdad se ha de plantear, por tanto, en el marco de estas experiencias atemáticas y a partir de su tematización.

Pannenberg sostiene que para que una revelación (tematización de la atemática experiencia de sentido) pueda ser acogida como verdadera será preciso que muestre su capacidad para integrar los diversos elementos de la experiencia cotidiana; incluso de las experiencias que carecen de sentido, como son el dolor y el mal. Esto ha de ser así porque en la entraña misma de toda revelación religiosa se encuentra una pretensión de verdad. Tal pretensión es la que se ha de acreditar en la experiencia de sentido, así como ante su razón.

Por tanto, la revelación ha de mostrar su capacidad para explicar y comprender la realidad en su conjunto, sin incurrir en la temeridad de poner el discurso sobre Dios por encima y en lugar de Dios mismo. Esto último es algo propio de quien se deja llevar por el afán explicativo, al margen de toda actitud doxológica. La teología negativa tiene la virtud de recordar la limitación de toda aproximación humana al misterio de Dios, al subrayar su incognoscibilidad.

Ahora bien, reconocer nuestra limitación en el acercamiento al misterio de Dios no supone responder negativamente a la posibilidad de hablar fundadamente de él y de su revelación. Supone reconocer los lfmites de la capacidad humana para conocer la totalidad de la realidad, así como el carácter relativo y doxológico de todo discurso sobre Dios 45 .

Esta es la perspectiva general desde la que nuestro autor formula los objetivos de su teología de la revelación. Desde ella se entiende mejor su interés por resaltar la importancia de la teologia de la revelación como teología fundamen-

43. Cfr. ibid., p. 62.

44. Cfr. ibid., p. 71 .

45. Cfr. "Experiencia de sentido, religión y pregunta por Dios". en Diálogo Filosofico I (1985) pp. 26-30.

Digitalizado por Biblioteca "P. Florentino Idoate, S.J."

Universidad Centroamericana José Simeón Cañas 


\section{LA ANTICIPACION DE LO ULTIMO}

tal, su preocupación por mostrar la verdad de la idea de Dios, su creciente inquietud por exponer la verdad de Dios en las experiencias religiosas y la centralidad que concede a la verdad de la revelación de Dios en el actuar de Jesucristo.

\subsection{La importancla de la teología de la revelación como teología funda- mental}

En las actuales circunstancias, mostrar la verdad de la revelación cristiana ha de ser, apunta Pannenberg, la primera y casi exclusiva preocupación de los teólogos; incluso por encima de la urgencia que pueda suscitar la imperiosa necesidad de transformar la realidad. Nuestro autor considera que se está viviendo un momento crucial en la historia de la humanidad y que hay que afrontar la verdad de Dios directamente, sin huídas hacia adelante (por ejemplo, la apelací́n al mundo de los pobres, a los más desgraciados del mundo o a la mismísima revolución). Lo que está en juego no es la vocación transformadora y altruista de la humanidad o del cristianismo, sino el sentido mismo y la verdad de toda religión y, por tanto, de la misma fe y de la revelación cristiana46.

Ha llegado la hora de evidenciar la debilidad de toda argumentación construida sobre el consenso o de toda teología dogmáticamente asentada en la supuesta claridad y suficiencia de la Escritura. Hoy lo que se cuestiona es la verdad de la doctrina cristiana y la misma consistencia de la representación de Dios. La idea de Dios ha dejado de ser una verdad incuestionada e incuestionable para convertirse en una permanente hipótesis que sólo al final de los tiempos se podrá convertir en tesis. Esta hipótesis ha de medirse, en el interim que media entre el tiempo presente y el final, con otras alternativas y cosmovisiones, empleando, para ello, los mismos argumentos y medios que pro-

46. Pannenberg lo afirma con claridad y hasta con contundencia, en varios, El futuro de la religión, Salamanca, 1975. pp. 205-206: "El problema de la iglesia de los pobres es una de las cuestiones que con mucha frecuencia ha servido para que la cristiandad - como conjunto- haya reprimido su propia situación". Denuncia las posiciones románticas y el verbo inflamado, cuando no el flirteo, de algunos sectores de las iglesias europeas que no acaban de reconocer que la identificación con los pobres pasa por el abandono de las propias posiciones de bienestar y por confundir el "hacer algo por los pobres" con el "hacerse una Iglesia de los pobres". Y, sobre todo, arremete contra quienes juegan con el pensarniento de la revolución y entre tanto dejan el trabajo que quizá podríamos hacer aqui y hoy en nuestra situación eclesiástica, "una obra que acaso en unos años o en decenios ya no podremos intentar, pues tendremos que vérmoslas quizá con una reacción conservadora dentro de nuestras estructuras eclesiásticas. $Y$ entonces hemos perdido esta tarea, porque nos hemos dejado aturdir por estas ideas revolucionarias y por el pensamiento de una iglesia de losigpobiresdy posasilatsîteca "P. Florentino Idoate, S.J."

Universidad Centroamericana José Simeón Cañas 
porciona la razón humana.

La teología ha de reconocer, por tanto, el carácter controvertido e hipotético de la idea y revelación de Dios, aceptando que ya no se puede presuponer su exiştencia. Ha de mostrar la verdad de la revelación cristiana, antes de iniciar un discurso bajo el régimen de la fe. Ha de ser, antes que nada, una teología que asienta sus propios fundamentos, esto es, una teología fundamental. Obviar esta situación y restarle importancia, resaltando desmedidamente el compromiso transformador y refugiándose en él, equivale a soslayar el problema más urgente que hoy tienen planteando las diferentes religiones, el cristianismo y la misma humanidad. Si falta la verdad del sentido es difícilmente sostenible una entrega desinteresada y total sólo sobre la base de un imperativo categórico, por muy altruista que sea.

\subsection{Mostrar la verdad de la idea de Dios}

Esta reconducción, al menos en primera instancia, de toda clase de teología a la teología fundamental resulta de la creciente insignificatividad de Dios en la cultura ilustrada y secular. La representación de Dios está perdiendo, efectivamente, su función de significar el fundamento y el destino último de la realidad. Ello obliga a reconsiderar la actual viabilidad y el sentido de las llamadas pruebas de la existencia de Dios. Pero impulsa, sobre todo, a considerar qué es lo que realmente puede decir el sujeto humano sobre Dios y hasta dónde puede llegar a partir de su congénita limitación.

Descalificados tanto el autoritarismo teológico como el irracionalismo subjetivista, ¿es posible afirmar algo sobre la verdad y la naturaleza de Dios? Esta es una de las tareas más urgentes de toda teología de la revelación: recuperar el sentido - cuando menos en clave antropológica - de la idea misma de Dios, explicitar el contenido a que se refiere tal concepto y analizar la consistencia de lo que se apunta en la llamada experiencia de Dios.

\subsection{Mostrar la verdad de Dios en las experiencias religiosas}

La razón, a partir de la radicación y destinación atemática, no puede ir más allá de postular la existencia de Dios y entregarse rendidamente a él. La experiencia del fundamento último de la realidad y del destino de la humanidad es, por tanto, experiencia de estar radicados y destinados —cierto que de manera todavía implícita - a una realidad que es independiente de la voluntad humana. Por tanto, la idea de Dios no puede ser única y exclusivamente fruto o resultado del discurrir humano o de la capacidad creativa de la naturaleza humana.

Mostrar la verdad y la entidad de Dios remite, por ello, a los archivos históDigitalizado por Biblioteca "P. Florentino Idoate, S.J."

Universidad Centroamericana José Simeón Cañas 
ricos de estas experiencias de fundamentalidad y sentido que son las religiones. A través de ellas es como se está posibilitando el conocimiento de Dios. $\mathrm{El}$ concepto de religión pasa a tener, por ello, una importancia similar a la que tuvo en la teología más tradicional la inspiración verbal. Y la explicación es bien sencilla: el contenido de la religión sólo puede ser establecido por la misma religión. Y dicho contenido, según Pannenberg, se manifiesta transcendiendo la experiencia subjetiva y es irreducible a mera antropología47.

Por tanto, nuestro autor no sólo pretende mostrar el estrechísimo nexo que se da entre la religión y la antropología, sino también la verdad que se puede atisbar en las diversas y diferentes manifestaciones religiosas, así como su referencia y relación con la verdad revelada. Por consiguiente, toda teologla significativa y significante ha de hundir sus raíces en las manifestaciones históricas del fundamento último que son las religiones. Aquí radica el cimiento más sólido de toda teología y, por tanto, de la teologla de la revelación.

\subsection{Mostrar la centralidad de la revelación de Dios en el actuar de Jesu- cristo}

Sólo muy recientemente, a partir de Hegel y Barth, ha ido cobrando relevancia el concepto de revelación, al percibirse la imposibilidad de que el ser humano llegue a conocer a Dios con sus solas fuerzas. No es posible, y Pannenberg abunda en esta consideración, ni la adoración ni la palabra sobre Dios si él no tiene a bien darse a conocer, revelarse.

Pareja a tal constatación y toma de conciencia ha transcurrido la pregunta por la verdad de la revelación de Dios en el actuar de Jesús de Nazaret. Pannenberg defiende la tesis de que una religión (en cuanto tematización de la experiencia de sentido) es verdadera cuando se da una coincidencia entre la verdad anticipada y atemálicamente presupuesta con la verdad final, en cuanto verdad y destino definitivo de todos y de cada uno de los seres humanos 48 .

Por ello, lo propio de la teología de la revelación consistirá en mostrar, a la espera de su comprobación definitiva, la verdad de la doctrina cristiana, tanto por referencia a otras cosmovisiones filosóficas como por relación a ouras religiones. La comprobación de tal pretensión de verdad se ha de efectuar analizando críticamente las mediaciones históricas en que se produce la revelación, aquilatando la idea que el sujeto humano y el teólogo se van haciendo de Dios y mostrando la importancia suma que dicha revelación tiene para la autocomprensión del sujeto humano.

47. Cfr. Systematische Theologie, pp. 139-140.

48. Cfr. ibid, p. 218. 
Una vez más, la historia, la idea de Dios y la antropología vuelven a reaparecer íntimamente conexas en el sistema teológico de Pannenberg49. Este es el contexto en el que queda enmarcado el objetivo fundamental de su teología de la revelación: mostrar la centralidad de dicha revelación en el actuar de Jesucristo y su indudable relevancia para la humanidad50. Pannenberg retomará y considerará los modos como se produce tal revelación a saber, como acontecimiento histórico y como anuncio iluminador, cuya radicación definitiva se encuentra en un final que se anticipa provisionalmente y cuyo sentido puede ser experimentado en el presente.

49. Cfr. ibid., p. 223.

50. Pannenberg recuerda la importancia de que este debate sirva para exponer y ayudar a descubrir la originalidad del cristianismo no sólo en relación a otras religiones, sino, sobre todo, en relación al destino que aguarda a la misma humanidad. Dicha originalidad estriba en anunciar aquello que el mundo no puede decirse a sf mismo, es decir, el mensaje de redención y superación del pecado y de la muerte a través de la cruz y resurrección de Jesús. Cfr. M. Fraijo, pp. 280-281. 